\title{
Changes in the QRS complex after aortic valve replacement
}

\author{
F. Follath ${ }^{1}$ and W. R. Ginks ${ }^{2}$ \\ From the Unit of Clinical Cardiology, Department of Medicine, Royal Postgraduate \\ Medical School, London
}

The electrocardiograms of 50 patients after isolated aortic valve replacement were examined. Two main types of postoperative $Q R S$ changes were found. In 13 patients intraventricular conduction defects developed, predominantly in the form of a left anterior hemiblock as an isolated lesion or combined with other focal blocks. The other prominent finding was the appearance of abnormal $Q$ waves suggesting inferior wall infarction in 8 patients, and anterior wall infarction in one.

Intraventricular conduction defects were interpreted as evidence of involvement of the conducting system during removal of the abnormal valve, whereas uneven myocardial blood flow during coronary perfusion was thought to be responsible for the appearance of abnormal $Q$ waves. The clinical importance of these findings is discussed.

Interest in intraventricular conduction defects has recently been renewed by Rosenbaum et al. (1969a). They showed the trifascicular character of the conduction system and introduced the term 'hemiblock' to describe conduction disturbances in one of the two divisions of the left bundle. Left anterior hemiblock was defined by left axis deviation between $-30^{\circ}$ and $-90^{\circ}$, initial $Q R S$ forces directed inferiorly and to the right, and slight prolongation of the QRS duration by 0.02 sec or less (Rosenbaum et al., I969c). Left posterior hemiblock was characterized by right axis deviation to $+120^{\circ}$, superiorly directed initial forces, and terminal QRS forces to the right and inferiorly (Rosenbaum et al., 1969b; Castellanos et al., I969).

Focal conduction defects not only change the QRS complex profoundly, thus obscuring the signs of ventricular hypertrophy and myocardial infarction, but they may be the first warning of complete atrioventricular block which may threaten life. Considering the anatomical relation of the bundle of His and its main branches to the ventricular septum and the aortic valve (Fig. I), mechanical injury to these structures seems likely to

Received 7 June 1971.

1 Present address: Department of Cardiac Surgery, Buergerspital, Basle, Switzerland.

2 Present address: Department of Medicine, University Hospital of San Diego County, 225 West Dickinson Street, San Diego, California 92103 , U.S.A. develop during cardiac surgery. Atrioventricular block and bundle-branch block are well-known complications after closure of ventricular septal defects (McGoon, Ongley, and Kirklin, 1964; Kulbertus, Coyne, and Hallidie-Smith, 1969) and the frequent development of left parietal block after transventricular aortic valvotomy has also been reported (Samson and Bruce, 1962). Aortic valve replacement, when coronary perfusion and cross-clamping of the aorta present additional hazards to the myocardium, seems to carry an increased risk of intraventricular conduction defects. In recent reports on valve replacement, the occasional production of atrioventricular block has been described (Kloster, Bristow and Griswold, 1965; Gannon et al., 1965) but the incidence of bundle-branch block or changes of the electrical axis were not mentioned.

In this paper, the electrocardiographic changes were analysed in 50 patients in order to investigate postoperative abnormalities of the QRS complex.

\section{Patients and methods}

Fifty patients undergoing isolated aortic valve replacement between 1967 and 1970 were included in this study (42 Starr-Edwards valves, 7 homografts, and I fascia lata repair). The only criterion for inclusion in this study was the availability of a 12 lead pre- and postoperative electrocardiogram. Patients who died in the immediate 


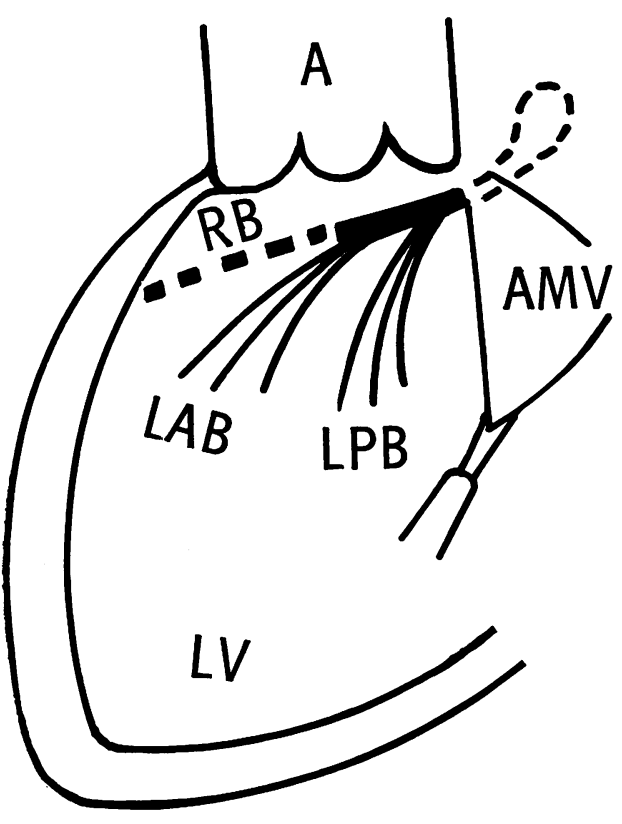

FIG. I Schematic representation of the intraventricular conducting system viewed from the left ventricle ( $L V)$ showing its relation to aortic and mitral valves. $A=$ aorta; $A M V=$ anterior mitral leaflet; $L A B=$ anterior division of the left bundle; $L P B=$ posterior division of the left bundle; $R B=$ right bundle-branch (coursing the right ventricular septal surface). (Modified after Hudson, 1967.)

postoperative period without having a complete electrocardiogram recorded were thus excluded from the series. There were no late deaths among the patients.

The electrocardiograms were analysed for changes of the QRS complex with special emphasis on the following criteria. (I) Initial ventricular activation (0.02 sec vector); (2) frontal plane QRS axis; (3) terminal QRS forces; (4) duration of the QRS complex. Serial postoperative electrocardiograms were reviewed to examine the evolution of the different changes.

The routine procedure at valve replacement consisted of (I) initiation of cardiac bypass and cooling to $32^{\circ} \mathrm{C}$; (2) aorta cross-clamped and opened; (3) perfusion of both coronary arteries to maintain a pressure of $70-90 \mathrm{mmHg}$ (mean); (4) fibrillation of the heart; (5) excision of the abnormal valve and valve replacement.

Operative data relating to coronary perfusion and aortic clamping, the state of the aortic valve, and the site of calcification and its subvalvular extension, were analysed. The early postoperative course was also studied in each patient.

\section{Results}

The electrocardiographic changes in the 50 patients after aortic valve replacement are listed in the Table.

(a) Preoperative abnormalities In 7 patients there was evidence of pre-existing intraventricular conduction defect. In one there was complete heart block which regressed after operation to right bundlebranch block with left anterior hemiblock. Three patients had complete left bundlebranch block before operation; I developed right bundle-branch block with left anterior hemiblock after operation, another regressed to left anterior hemiblock and in the other patient left bundle-branch block persisted after operation. Three further patients had left anterior hemiblock before operation and this conduction defect persisted after valve replacement.

In I patient there were abnormal $Q$ waves in leads II, III, and aVf before operation. This patient developed changes suggesting anterior wall infarction after operation, the details of which are discussed later.

(b) Postoperative development of intraventricular conduction defects The different types of intraventricular conduction defect occurring after operation are schematically represented in Fig. 2.

Damage to all three fascicles (trifascicular block) was found in 2 patients. The first developed complete AV block during operation, needing artificial pacing for three days. The electrocardiogram subsequently changed to left bundle-branch block with first degree

TABLE $Q R S$ changes in 50 patients after aortic valve replacement

(I) Preoperative pre-existing abnormalities (8 patients)

(a) Conduction defects

Trifascicular block

Bifascicular block

Left anterior hemiblock

(b) Abnormal $Q$ waves in leads II, III, aVF

(2) Postoperative changes (22 patients)

(a) Conduction defects

Trifascicular block

Bifascicular block

Left anterior hemiblock

(b) Abnormal $Q$ waves

In leads II, III, aVF

In $\mathrm{VI}_{\mathrm{I}} \mathrm{V}_{4}$ 
AV block and later to left anterior hemiblock (Fig. 3). During follow-up, left bundlebranch block returned several times with tachycardia. The second patient had left bundle-branch block before operation which changed to right bundle-branch block with left anterior hemiblock after valve replacement (Fig. 4).

Bifascicular block developed in 2 patients. Normal intraventricular conduction changed to right bundle-branch block with left anterior hemiblock in one (Fig. 5) and to left bundlebranch block in the other.

Left anterior hemiblock was the most frequent finding. In 6 patients, there was abnormal left axis deviation with an inferiorly directed initial vector and minimal widening , of the QRS complex (<0.12), thus fulfilling the necessary criteria (Fig. 6). In 3 other patients, the electrocardiographic patterns were considered to be compatible with incomplete left anterior hemiblock showing left axis deviation to $-15^{\circ}$ and a change of the initial QRS vector only (Fig. 7).

(c) Postoperative development of abnormal $Q$ waves This group of patients showed initial $Q R S$ vectors suggesting myocardial infarction. In 8 patients, abnormal $Q$ waves developed in leads II, III, and aVF (Fig. 8).

In these patients, there was no significant change in the mean QRS axis, with the exception of one patient who also developed left axis deviation to $-45^{\circ}$. One additional patient showed loss of the praecordial $\mathbf{R}$ waves and changes of left anterior hemiblock (Fig. 9). That axis shift was not the cause for this appearance was substantiated when praecordial leads taken higher on the chest wall still revealed the same pattern suggesting $\checkmark$ anterior wall infarction.

(d) No postoperative change In a group of 20 patients, the QRS complex was normal before operation and remained so after valve replacement. At operation there was no evidence of subvalvar calcification and both

- coronary arteries were perfused without difficulty. The postoperative course in these patients was uneventful.

(e) Correlation of electrocardiographic changes with operative data (I) Type of valve replacement $A$ total of 42 patients had Starr-Edwards valves and, of these, I2 developed postoperative conduction defects, 8 developed postoperative $Q$ waves, and in the remaining 22 patients there was no change in the postoperative cardiogram.
Seven patients had homograft valve replacements and, of these, I developed a postoperative conduction defect, I developed postoperative $Q$ waves, and in the remaining 5 patients there was no change in the postoperative electrocardiogram.

One further patient had a fascia lata valve replacement without any change in the cardiogram.

\section{INTRAVENTR ICULAR CONDUCTION DEFECTS AFIER}

$$
\text { AORTIC VALVE REPLACEMENT }
$$

PREOPERATIVE E.C.G.

POSTOPERATIVE E.C.G.

$$
\text { EARLY }
$$

LATER
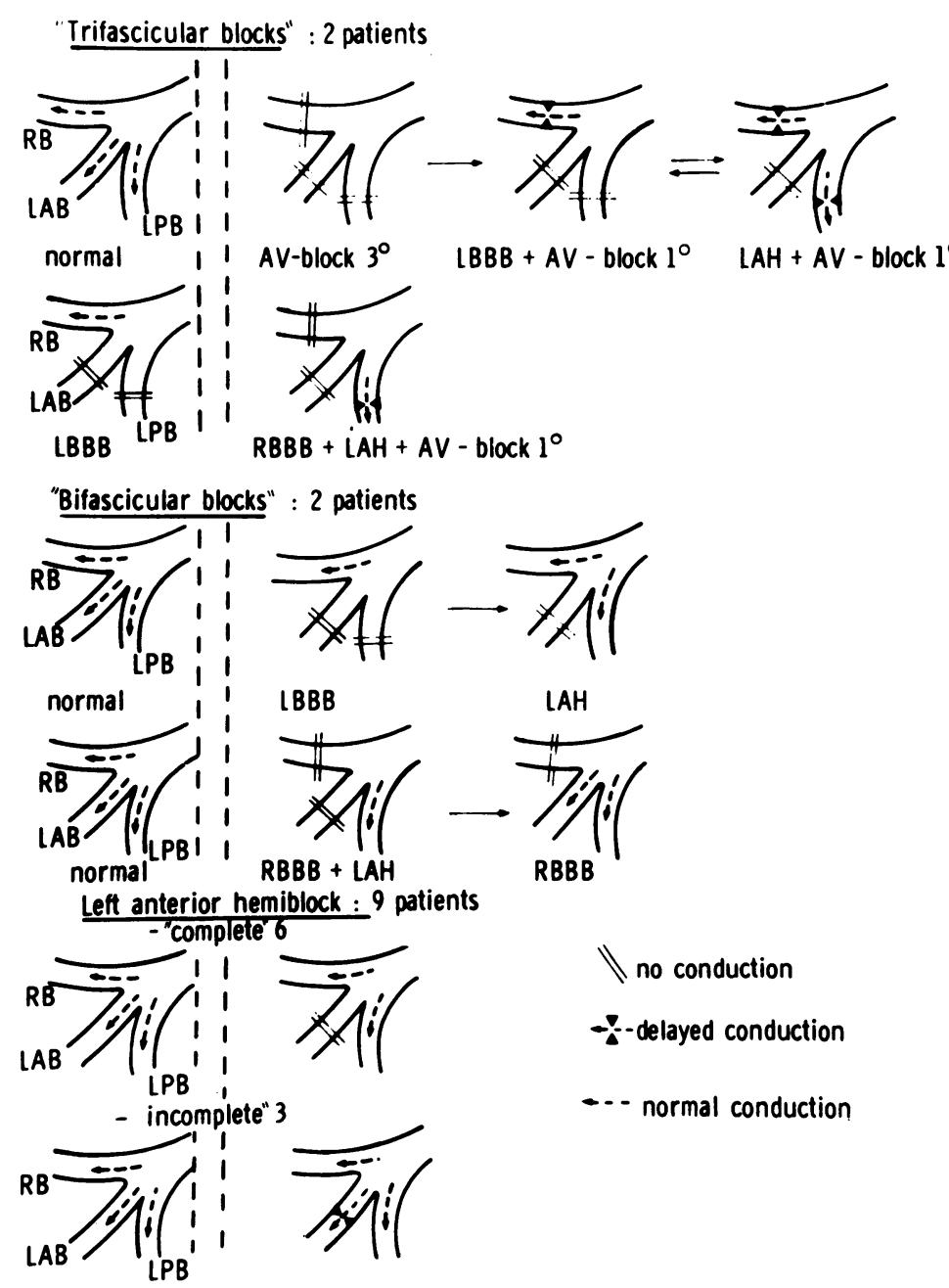

FIG. 2 Graphic representation of the intraventricular conduction defects. 
(2) Coronary perfusion Of the 50 patients, 42 had both right and left coronary arteries perfused during operation. Thirteen of these patients developed postoperative conduction defects, i.e. all patients with conduction defects had both coronaries perfused. A further 5 developed postoperative $Q$ waves, including 2 patients in whom blood flow in the right coronary artery was inadequate and had to be interrupted several times during operation and I patient in whom anomalies of the right and left circumflex coronary arteries were shown by preoperative coronary angiography. The remaining 24 patients showed no change in the postoperative cardiogram.

In the remaining patient, the aorta was clamped at $29^{\circ} \mathrm{C}$ for 45 minutes without any form of coronary perfusion but this patient showed no postoperative electrocardiographic changes.

(3) Calcification of aortic valve Heavy calcification of the aortic valve with subvalvar extension of calcium was described by the surgeon in 9 patients; 2 already had preexisting preoperative conduction defects, 4 developed postoperative conduction defects, I developed postoperative $Q$ waves, and in the remaining 2 patients there was no change in the electrocardiogram after operation.

\section{Discussion}

The incidence of postoperative electrocardiographic changes was high after aortic valve replacement. The abnormalities observed suggest damage to the conducting system and myocardium since the QRS complex, in contrast to the phase of repolarization, is not usually influenced by digitalis, antiarrhythmic agents, electrolyte changes, and pericardotomy.

Of the patients with intraventricular conduction defects, involvement of the anterior division of the left bundle was present in all, a feature that is not surprising when the close relation of this structure to the aortic valve is considered (Lev, 1964). The shift of the mean QRS axis and the change in initial ventricular activation in 3 patients were interpreted as indicating partial interruption of the left anterior fibres, that is, incomplete left anterior hemiblock. The existence of incomplete left anterior hemiblock, however, is still uncertain (Rosenbaum et al., 1969c). Right bundle-branch block was found in 4 patients, and a transient conduction defect in the left posterior bundle, never occurring as an isolated lesion, was also noted in $4 \mathrm{pa-}$ tients.

The pathogenesis of the conduction defects
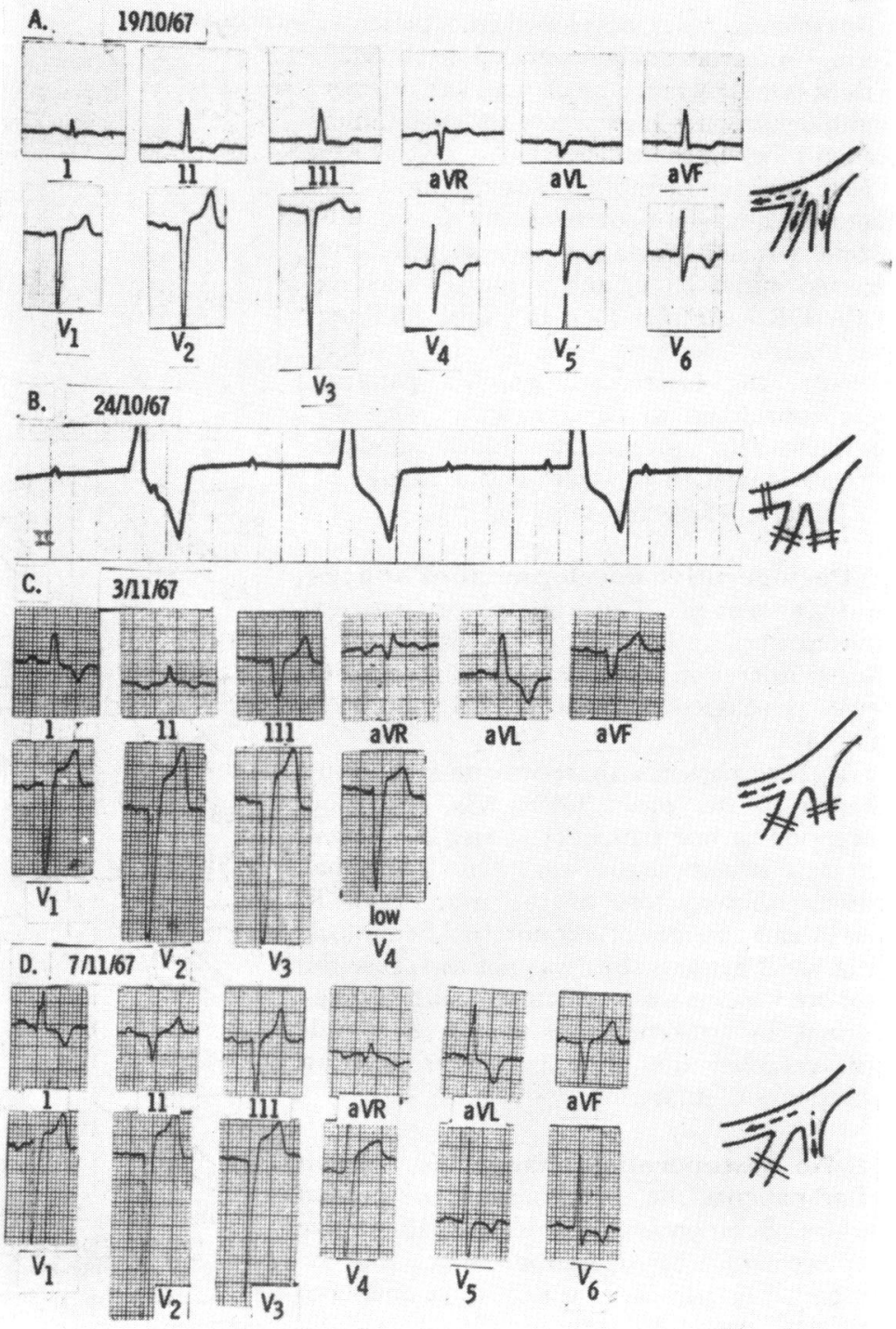

FIG. 3 'Trifascicular' block. Normal preoperative intraventricular conduction $(A)$ changing to complete AV block immediately after operation $(B)$ and later to left bundle-branch block $(C)$ and left anterior hemiblock $(D)$. 


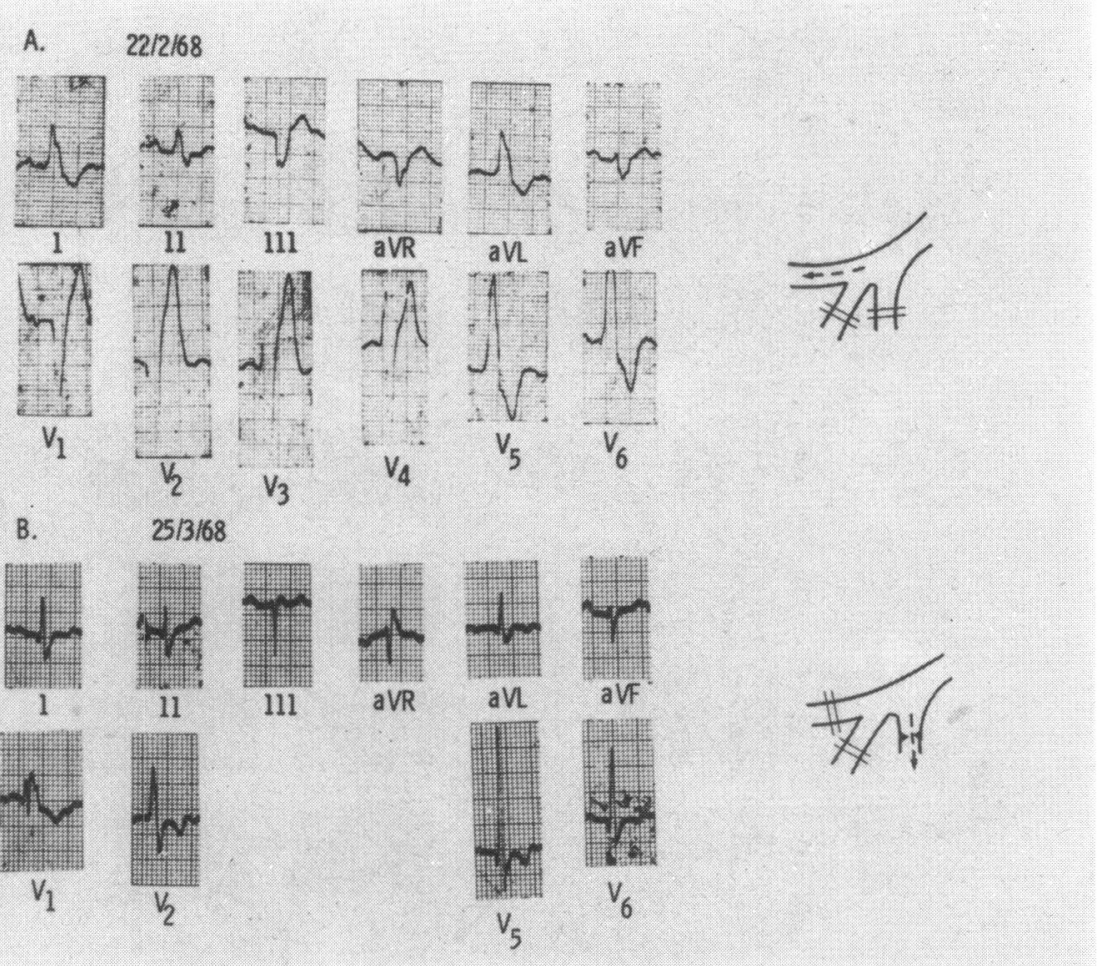

FIG. 4 'Trifascicular' involvement of the conduction system. Preoperative left bundle-branch block $(A)$ changing to right bundle-branch block and left anterior hemiblock after valve replacement $(B)$.

is probably due to involvement of the conducting system during removal of the abnormal valve. Haemorrhagic lesions and necrosis of the atrioventricular conducting system have been observed not infrequently after aortic valve replacement (Hudson, 1967; Niles and Sandilands, 1969). Whether con-

" duction defects are more likely to develop after Starr-Edwards valve insertion than after homograft valve replacement is uncertain, since the two procedures are not equally represented in this series.

The second prominent finding was the development of abnormal $Q$ waves suggesting

- inferior infarction in 8 patients, and anterior wall infarction in I patient. Attention has been drawn to the association between these

- changes and the difficulties of coronary artery perfusion. An alternative explanation, however, which might account for the appearance of $Q$ waves in the inferior leads is a

- conduction disturbance in the left posterior

- bundle. Experimental dissection of the left posterior bundle in primates produces an electrocardiographic pattern resembling inferior wall infarction (Watt and Pruitt, 1969).
Left posterior hemiblock has also been shown clinically to cause a shift of the initial QRS vector superiorly and therefore $Q$ waves in leads II, III, and aVF (Rosenbaum et al., I969b). Recently the spontaneous development of wide slurred $Q$ waves in the inferior leads was described in patients with aortic valve disease without any evidence of coronary artery disease (Warembourg et al., 1970). These authors suggested that the regurgitant jet of aortic incompetence was responsible for the abnormal $Q$ waves by causing endocardial fibrosis in the area of the left posterior bundle. One of the accepted criteria of left posterior hemiblock is, however, a rightward shift of the mean frontal plane QRS axis, which is not a feature in our patients with inferior $Q$ waves.

In conclusion, the frequency of intraventricular conduction defects after aortic valve replacement emphasizes the important anatomical relation between the conducting system and the aortic valve cusps. In addition, the development and variability in the types of intraventricular blocks lend further support to the concept of trifascicular intra- 


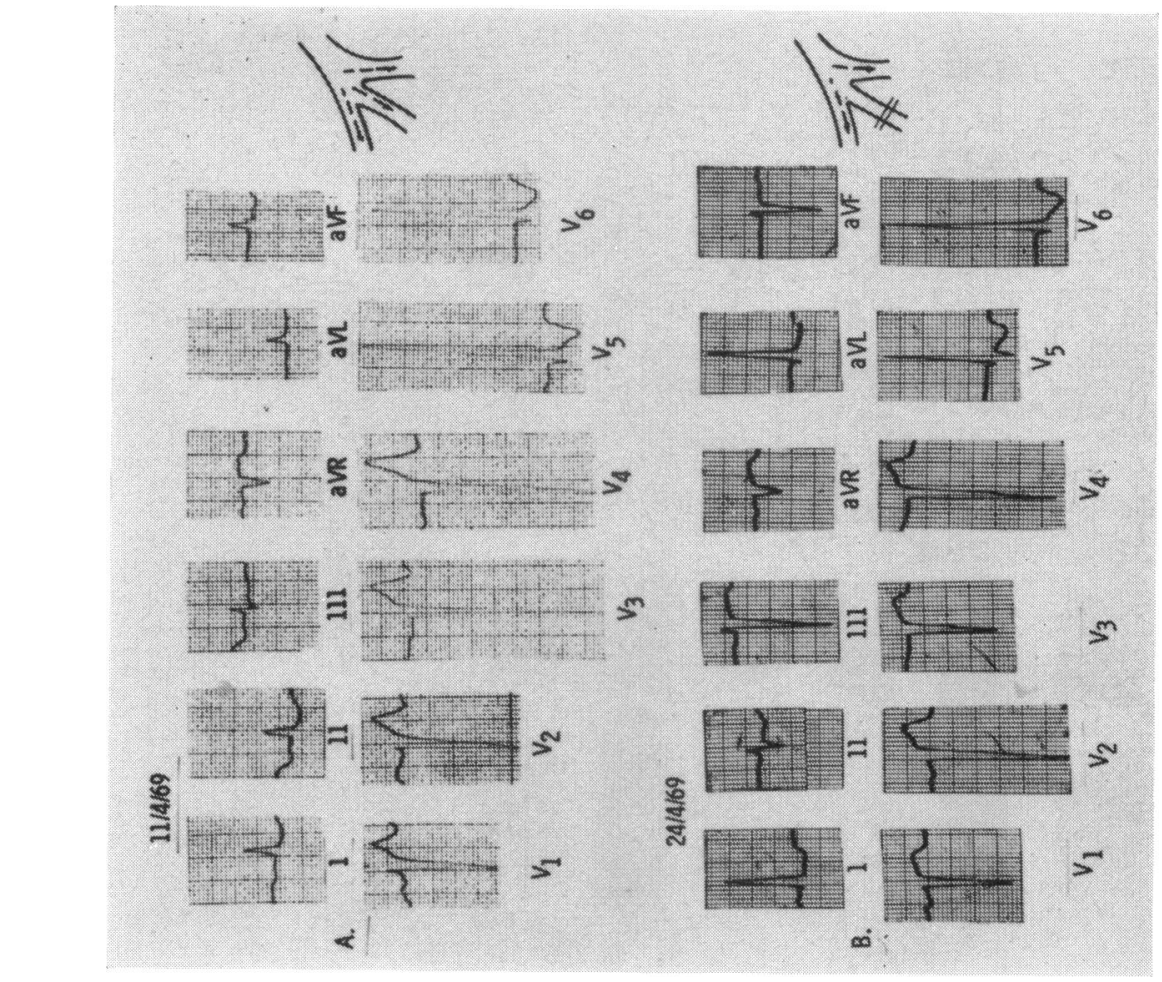

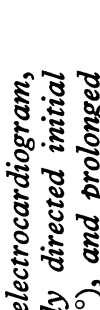

号

․ำ

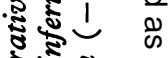

ఫัฐ

देष्ठ

ड密

संद्वा क्ष

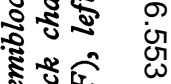

हूँิ

ปูำ

ะู

है. ปิ

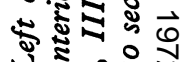

ประกำ

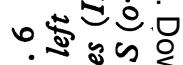

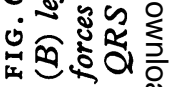

$\sqrt{i \frac{\pi}{i n}}$

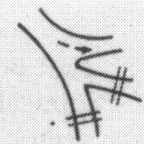

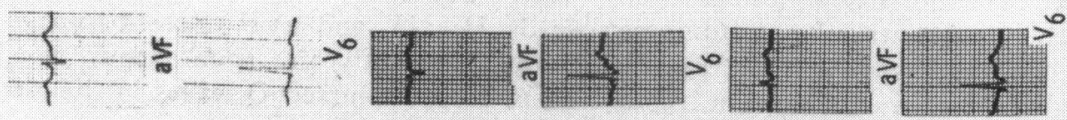

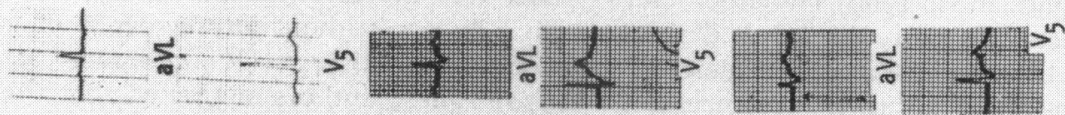

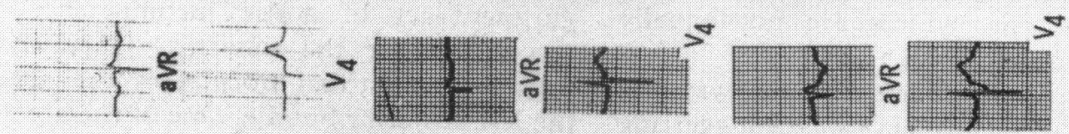
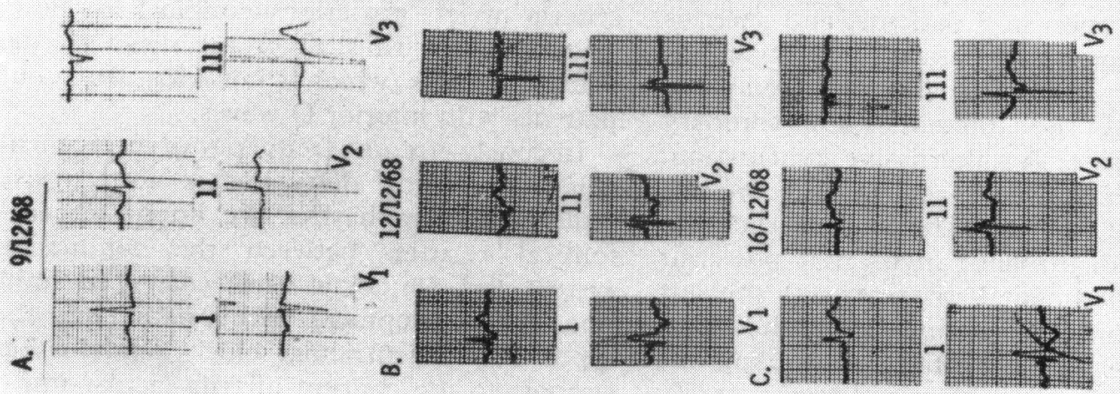

i⿱

.

离.

रूल

स:

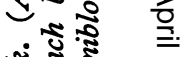

กั ถู

ปั่

ఫี ฐँ

. है है

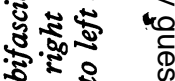

गั.

-

ฐँ क्षे

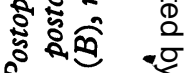

a

n芯芯

की 

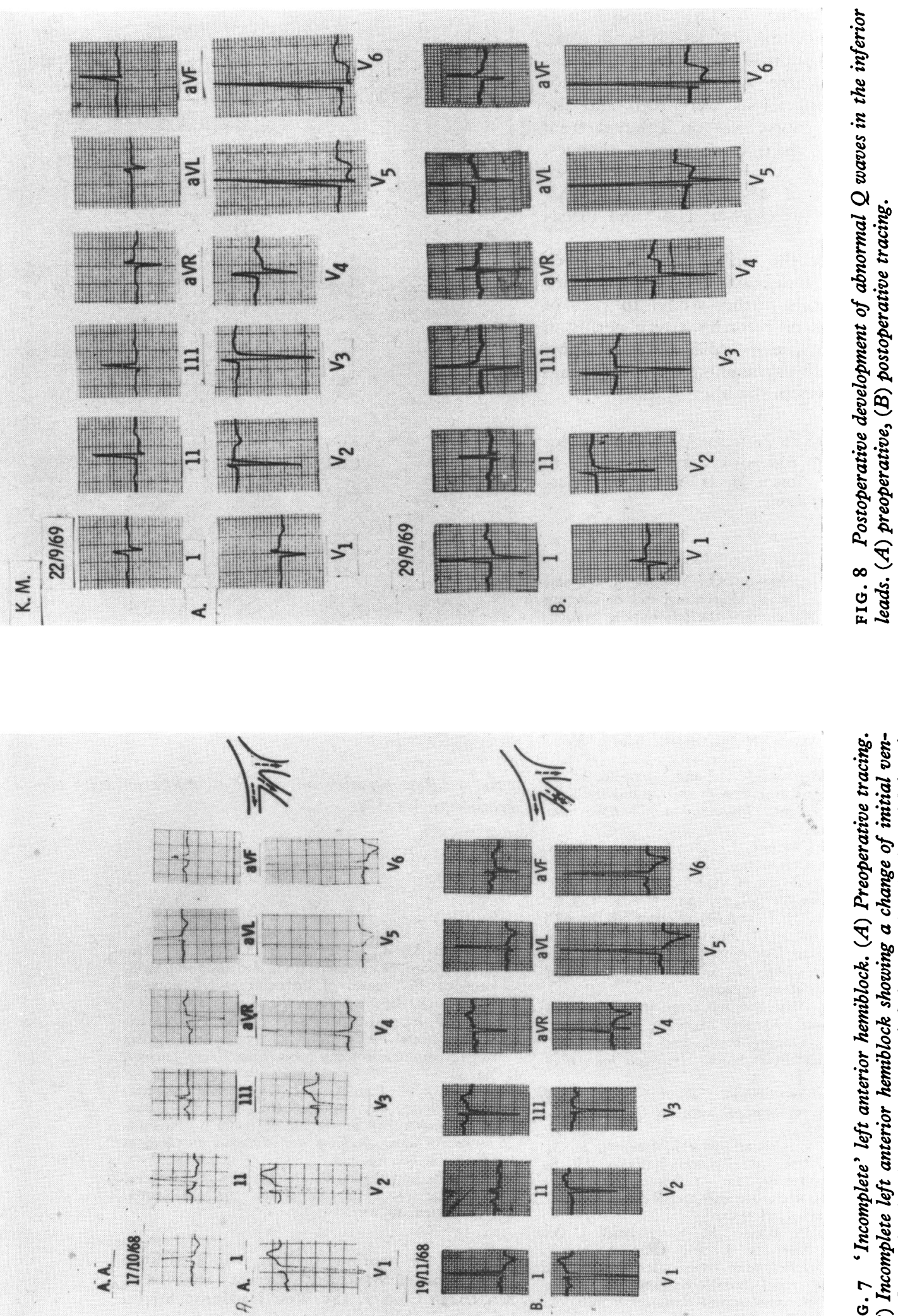

मู० है

․․ㄹ

$\frac{9}{7}$

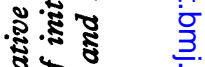

कूั

हैำ

ङัष

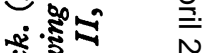

ర్

₹

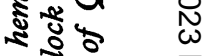

ป :

हूँ है

-.ำ

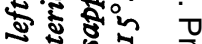

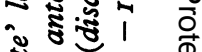

ธั้ธัธ

넝 $\frac{1}{2}$

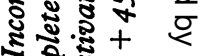

约

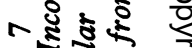

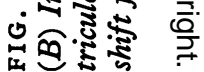


ventricular conduction. The clinical importance of these conduction defects is not clear. With the exception of the patient with transient third degree AV block, no haemodynamic complications were seen and the postoperative course was no different from those without electrocardiographic changes. Nevertheless, it is possible that there is an increased risk of developing complete AV block in later life (Lasser, Haft, and Friedberg, 1968).

At present, the differentiation between inferior wall infarction and left posterior hemiblock awaits further study. In view of the difficulties of coronary artery perfusion in our patients, myocardial necrosis seems the most likely explanation for the appearance of $Q$ waves in the inferior leads.

We are indebted to Professor J. F. Goodwin for helpful criticism and advice, and to Mr. W. P. Cleland and Professor H. H. Bentall who performed the operations.

\section{References}

Castellanos, A., Jr., Maytin, O., Arcebal, A. G., and Lemberg, L. (1969). Alternating and co-existing block in the divisions of the left bundle branch. Diseases of the Chest, 56, 103.

Gannon, P. G., Sellers, R. D., Kanjuh, V. I., Edwards, J. E., and Lillehei, C. W. (1965). Complete heart block following replacement of the aortic valve. Circulation, 33-34, Suppl. I, I52.

Hudson, R. E. B. (1967). Surgical pathology of the conducting system of the heart. British Heart fournal, 29, 646.

Kloster, F. E., Bristow, J. D., and Griswold, H. E. (I965). Medical problems in mitral and multiple valve replacement. Progress in Cardiovascular Diseases, 7, 504.

Kulbertus, H. E., Coyne, J. J., and Hallidie-Smith, K. A. (1969). Conduction disturbances before and after surgical closure of ventricular septal defect. American Heart fournal, 77, 123.

Lasser, R. P., Haft, J. I., and Friedberg, C. K. (I968). Relationship of right bundle-branch block and marked left axis deviation (with left parietal or peri-infarction block) to complete heart block and syncope. Circulation, 37, 429.

Lev, M. (1964). Anatomic basis for atrioventricular block. American fournal of Medicine, 37, 742 .

McGoon, D. C., Ongley, P. A., and Kirklin, J. W. (1964). Surgical heart block. American fournal of Medicine, 37, 749.

Niles, N. R., and Sandilands, J. R. (1969). Pathology of heart valve replacement surgery. Diseases of the Chest, 56, 373.

Rosenbaum, M. B., Elizari, M. V., Lazzari, J. O., Nau, G. J., Levi, R. J., and Halpern, M. S. (1969a). Intraventricular trifascicular blocks. Review of the literature and classification. American Heart fournal, 78, 450 .

Rosenbaum, M. B., Elizari, M. V., Lazzari, J. O., Nau, G. J., Levi, R. J., and Halpern, M. S. (1969b). Intraventricular trifascicular blocks. The syndrome of right bundle-branch block with intermittent left anterior and posterior hemiblock. American Heart fournal, 78, 306.

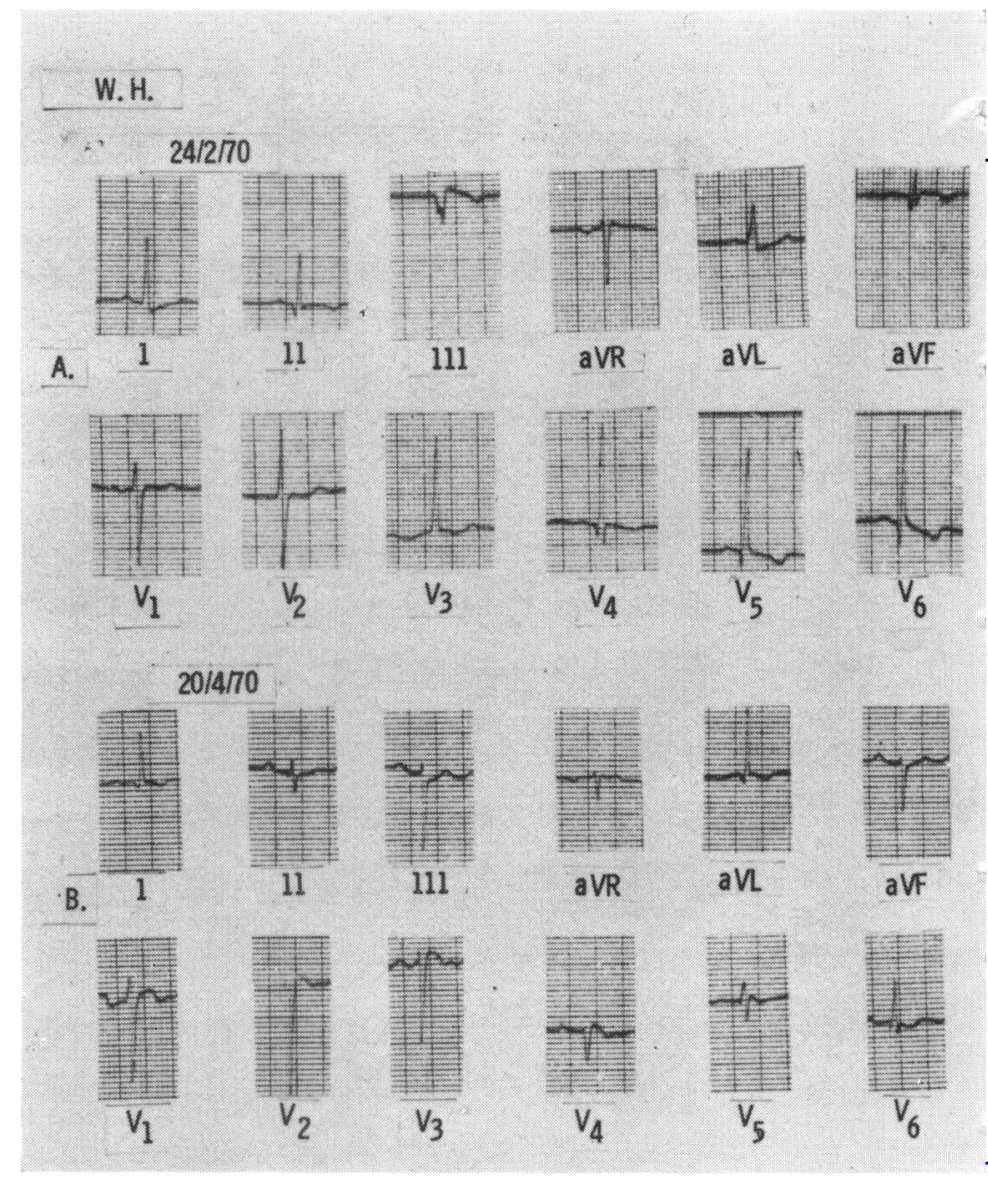

FIG. 9 Postoperative anterior wall infarction with poor $R$ wave progression in $V_{I}-V_{3}$.

Rosenbaum, M. B., Elizari, M. V., Levi, R. J., Nau, G. J., Pisani, N., Lazzari, J. O., and Halpern, M. S. (1969c). Five cases of intermittent left anterior hemiblock. American fournal of Cardiology, 24, I.

Samson, W. E., and Bruce, R. A. (1962). Left ventricular parietal block produced by transventricular aortic commissurotomy. American Heart fournal, 63, 4I.

Warembourg, H., Pauchant, M., Thery, Cl., Lekieffre, J., Ducloux, G., and Gosselin, B. (I970). Bloc intraventriculaire posterieur au cours de l'insuffisance aortique. Archives des Maladies du Cour et des Vaisseaux, 63, 408.

Watt, T. B., and Pruitt, R. D. (1969). Left posterior fascicular block in canine and primate hearts. Circulation, 40, 677.

Requests for reprints to Dr. W. R. Ginks, Department of Medicine, University Hospital of San Diego County, 225 West Dickinson Street, San Diego, California 92 ro3, U.S.A. 